\title{
Lymphocyte Transformation by Pollen Extracts and Purified Protein Derivative (PPD) in Leukocyte Cultures of Normal Human Subjects
}

\section{Description of Findings and Conditions Required 1}

\author{
Kenneth P. Mathews, Pauline M. Pan, and Stephen C. Weisberg ${ }^{2}$ \\ Montgomery Allergy Research Laboratory, Department of Internal Medicine, \\ University of Michigan Medical School, Ann Arbor, Michigan 48109
}

Received January 3, 1977

\begin{abstract}
It is shown in a large number of experiments that short ragweed extract, mixed-grass pollen extract, and purified protein derivative (PPD) can produce very substantial tritiated thymidine uptake and lymphocyte blast transformation of peripheral blood leukocytes from normal individuals. Cord blood lymphocytes were also stimulated by pollen extracts. Differing conditions of culture probably explain the discrepancy between these results and many previous studies in which normal cells were not stimulated by these agents. Of particular importance are the use of human plasma in the cultures, restricted washing of the cells, the culture medium, and prolonged (8-day) cell culture times. Heparin has considerable influence on the results.
\end{abstract}

\section{INTRODUCTION}

Several laboratories have reported lymphocyte transformation by pollen extracts or ragweed antigen $E$ when leukocytes from pollen-sensitive individuals were employed (1-17). With few exceptions $(6,17)$, control cultures of cells from nonsensitive subjects showed no lymphocyte transformation. Thus we were surprised to find pronounced transformation of lymphocytes from "normal" humans with pollen extracts (18) under the conditions of culture being used in our laboratory for other purposes (19). The present report describes these findings and the conditions required. It is also shown that $\mathrm{PPD}^{3}$ will regularly produce transformation of lymphocytes from tuberculin-negative humans under similar conditions.

1 This work was supported in part by Grant No. AI 10134 from the National Institutes of Health, Bethesda, Maryland.

2 Address correspondence to Kenneth P. Mathews, M.D., Montgomery Allergy Research Laboratory, R6621 Kresge Medical Research Building I, University of Michigan Medical Center, Ann Arbor, Michigan 48109.

3 Abbreviations used: AP, autologous plasma; AS, autologous serum; BCG, Bacillus Calmette-Guérin; BGG, bovine $\gamma$-globulin; BSA, bovine serum albumin; DNP, dinitrophenol; EDTA, ethylenediaminetetraacetic acid; FCS, fetal calf serum; HEPES, 4-(2-hydroxyethyl)1-piperazinepropanesulfonic acid; $\left[{ }^{3} \mathrm{H}\right] \mathrm{Tdr}$, tritiated thymidine; $\mathrm{KLH}$, keyhole limpet hemoglobin; LPS, lipopolysaccharide; MEM, minimal essential medium; MEM-S, minimal esscntial medium for suspension cultures; MGE, mixed-grass extract; NPBL, normal peripheral blood leukocytes; PBS, phosphate-buffered saline; PHA, phytohemagglutinin; PPD, purified protein derivative; RBC, red blood cells; SI, stimulation index; SRWE, short ragweed extract; TCA, trichloroacetic acid; TNP, trinitrophenol; WBC, white blood cells. 


\section{MATERIALS AND METHODS}

Methods of lymphocyte culture. Although numerous modifications are described under Results, the usual procedure employed is as follows: Venous blood is drawn into plastic syringes containing $150 \mathrm{U}$ of phenol-free heparin and $2.5 \mathrm{ml}$ of dextran (Pharmacia or Travenol ; average MW of 70,000 or 75,00 , respectively) per $10 \mathrm{ml}$. After mixing, the syringes are maintained in an upright position at $37^{\circ} \mathrm{C}$ for $90 \mathrm{~min}$. The leukocyte-rich supernatant is removed, the leukocytes are counted and the percentage of mononuclear cells noted. The cells are washed once in Eagle's MEM (Grand Island Biological Co., Grand Island, New York) and placed in a sterile plastic flask where additional components are added to provide $6.25 \times 10^{5}$ leukocytes $/ \mathrm{ml}$ of solution containing $20 \%$ autologous plasma, $219 \mu \mathrm{g}$ of glutamine, and $75 \mu \mathrm{g}$ of streptomycin in Eagle's MEM. Aliquots of $4.0 \mathrm{ml}$ with $0.1 \mathrm{ml}$ of added antigen, mitogen, or saline are cultured generally for 8 days at $37^{\circ} \mathrm{C}$ in tightly sealed upright plastic tubes (Falcon). Two or four hours prior to harvesting, $1.5 \mu \mathrm{Ci}$ of methyltritiated thymidine is added to each tube. At the termination of culture the cells are washed twice with cold saline and suspended in 10\% TCA. The resultant precipitate is washed in 5\% TCA. After carefully aspirating off the supernatant, the precipitate then is dissolved in 0.5 $\mathrm{ml}$ of NCS solubilizer (Amersham/Searle) and transferred in toluene-based scintillation fluid to counting vials. Counts per minute $(\mathrm{cpm})$ are measured in the cold in a Packard Tri-Carh scintillation counter. Cultures were run in triplicate, and in some instances the results also were assessed microscopically by the method of Bach and Hirschhorn (20) by counting 500 cells in a "blind" manner.

Antigens and mitogens. Pollens were purchased from Greer Laboratories, Lenoir, North Carolina, or Hollister-Stier Laboratories, Spokane, Washington. They werc defatted with diethyl cther in a Soxhlet apparatus, and $10 \%(\mathrm{w} / \mathrm{v})$ extracts were prepared as for clinicial use (21) except that no phenol or glycerin was included in the $\mathrm{pH}$ 8.0 PBS extracting fluid. The extracts were lyophilized for storage. After reconstitution they were passed through $0.45-\mu \mathrm{m}$ Millipore filters and frozen in aliquots at $-20^{\circ} \mathrm{C}$. Protein nitrogen content was determined by phosphotungstic acid precipitation (modified from Cooke (22)). Mixed-grass extract was prepared with equal amounts of timothy (Phleum pratense) and orchard grass (Datcylis glomerate) pollen. The PPD antigen generally used was a lyophilized preparation donated by Parke-Davis; it was dialyzed against PBS for $24 \mathrm{hr}$ to eliminate possible traces of cresol. Also used was preservative-free PPD prepared by TCA precipitation by the Connaught Laboratories, Willowdale, Ontario, Canada. PHA-P was purchased from Difco Laboratories, Detroit, Michiganl.

Experimental subjects. Blood donors were healthy young adult volunteers; all gave informed consent to participate. A brief history was taken with regard to symptoms of allergic disease, history of tuberculosis or past skin test reactivity to PPD, and general health. Prick and intracutaneous tests with relevant pollen extracts were performed usually after the first bleeding. The same procedure was used with respect to Mantoux testing with intermediate strength (5 tuberculin units) PPD (Parke-Davis). 
TABLE 1

$\left[{ }^{3} \mathrm{H}\right]$ TdR Uptake by Leukocytes of a "Normal" Subject Cultured for 8 Days

\begin{tabular}{cccc}
\hline $\begin{array}{c}\text { Protein N } \\
\text { SRW added } \\
(\mu \mathrm{g})\end{array}$ & $\begin{array}{c}\text { Counts per } \\
\text { minute }\end{array}$ & $\begin{array}{c}\text { Stimulation } \\
\text { index }\end{array}$ & $\begin{array}{c}\text { Change in } \\
\text { counts per } \\
\text { minute }^{b}\end{array}$ \\
\hline None & 360 & & \\
1.67 & 6,391 & 18 & 6,031 \\
5.0 & 17,498 & 49 & 17,138 \\
15.0 & 29,696 & 83 & 29,245 \\
45.0 & 5,239 & 15 & 4,879 \\
\hline
\end{tabular}

a Stimulation index : counts per minute observed/counts per minute control.

${ }^{b}$ Counts per minute observed - counts per minute control.

\section{RESULTS}

\section{Description of Findings}

Table 1 shows results of an early experiment in which leukocytes of an individual with no history of pollenosis and with negative skin tests to short ragweed extract showed pronounced $\left[{ }^{3} \mathrm{H}\right] \mathrm{TdR}$ incorporation after 8 days of culture with SRWE. This experiment is representative of 11 others in showing reduced lymphocyte stimulation with excess SRWE, although the optimal concentration varied with different lots of SRWE. In other experiments lymphocyte stimulation by SRWE was confirmed by microscopic enumeration of blast cells in cultures containing polystyrene particles to aid in the identification of macrophages; for example, $24.1 \%$ transformed cells (compared to $1.9 \%$ in unstimulated cultures) were observed after 8 days in culture with an optimal concentration of SRWE which produced an incremental $\left[{ }^{3} \mathrm{H}\right] \mathrm{TdR}$ uptake of $12,374 \mathrm{cpm}$ and a stimulation index (SI) of 38. Staining with erythrosin B indicated that $91-95 \%$ of the cells cultured for 8 days with SRWE were viable. SRWE also was shown to induce tritiated uridine uptake, though to a lesser extent than $\left[{ }^{3} \mathrm{H}\right] \mathrm{TdR}$ uptake under the conditions employed.

\section{TABLE 2}

[ $\left.{ }^{3} \mathrm{H}\right] \mathrm{TdR}$ Uptake by Leukocyte Cultures of "Normal" Subjects

\begin{tabular}{|c|c|c|c|c|c|}
\hline \multirow[t]{2}{*}{ Stimulant } & \multirow{2}{*}{$\begin{array}{l}\text { Number } \\
\text { of ex- } \\
\text { periments }\end{array}$} & \multicolumn{2}{|c|}{ Stimulation index } & \multicolumn{2}{|c|}{ Change in counts per minute } \\
\hline & & $\begin{array}{l}\text { Geomeltic } \\
\text { mean } \pm S D\end{array}$ & Range & $\begin{array}{c}\text { Geometric } \\
\text { mean } \pm \mathrm{SD}\end{array}$ & Range \\
\hline $\begin{array}{l}\text { SRWE } \\
\text { (A mbrosia elatior) }\end{array}$ & 192 & $\begin{array}{l}52 \\
(1.717 \pm 0.616)^{\circ}\end{array}$ & $\begin{array}{l}0-1,163 \\
(-3.066)\end{array}$ & $\begin{array}{c}8.541 \\
(3.931 \pm 0.615)\end{array}$ & $\begin{array}{c}0-102,420 \\
(-5.010)\end{array}$ \\
\hline $\begin{array}{l}\text { Mixed grass pollen } \\
\text { extract }\end{array}$ & 14 & $\begin{array}{c}122 \\
(2.085 \pm 0.546)\end{array}$ & $\begin{array}{c}33-2.289 \\
(1.516-3.360)\end{array}$ & $\begin{array}{c}27,246 \\
(4.435 \neq 0.374)\end{array}$ & $\begin{array}{c}7,014-157,413 \\
(3.846-5.198)\end{array}$ \\
\hline PPD & 67 & $\begin{array}{c}34 \\
(1.527 \pm 0.655)\end{array}$ & $\begin{array}{c}1-350 \\
(0-2.543)\end{array}$ & $\begin{array}{c}3,880 \\
(3.589 \pm 0.656)\end{array}$ & $\begin{array}{r}57-53,625 \\
(1.750-4.730)\end{array}$ \\
\hline PHA (3 days) & 35 & $\begin{array}{cl} & 691 \\
(2.84 & \pm 0.26)\end{array}$ & $\begin{array}{r}95-2,200 \\
(1.98-3.34)\end{array}$ & $\begin{array}{c}98.239 \\
\left(4.99^{ \pm} \pm 0.23\right)\end{array}$ & $\begin{array}{c}32,881-253,150 \\
(4.52-5.40)\end{array}$ \\
\hline PHA (8 days) & 72 & $\begin{array}{ll} & 145 \\
(2.16 & \pm 0.66)\end{array}$ & $\begin{array}{r}1-7.787 \\
(0-3.89)\end{array}$ & $\begin{array}{c}29,831 \\
(4.47 \quad \pm 0.47)\end{array}$ & $\begin{array}{l}80-111,294 \\
(1.90-5.05)\end{array}$ \\
\hline
\end{tabular}


Table 2 summarizes the results of 192 separate experiments in which the leukocytes of 42 "normal" subjects were cultured for 8 days with an optimal amount of SRWE under quite similar conditions. Excluded are 14 experiments where the cultures died or were technically unsatisfactory, but the results shown have been confirmed in many additional experiments under somewhat different conditions. Geometric means and standard deviations, calculated by $\log$ transformation of the data, were employed in expressing the values shown in Table 2, since these were skewed as a result of some very large counts per minute and some extremely high SI's in experiments where, in addition, the control counts per minute were very low. Most of the control counts per minute were in the range of 50-2000. In the 192 experiments employing SRWE, the SI was below 10.0 in 25 instances and below 3.0 in only three experiments. The change in counts per minute (counts per minute with stimulant minus counts per minute without stimulant) was less than 2000 in 20 instances and under $1000 \mathrm{cpm}$ in nine experiments out of 192 . As a means of expressing the variability of triplicate determinations, their coefficients of variation ( $\mathrm{SD} /$ mean) were ascertained in 25 consecutive experiments. They were $\pm 24 \%$ in experiments employing SRWE (mean $\mathrm{cpm}=13,247$ ) and $\pm 8.4 \%$ after 8 days in culture with PHA (mean cpm $=33,496$ ). When the coefficient of variation with PHA at 8 days was compared with that of SRWE in the same experiment, the former was smaller in 21 of 25 experiments. Thus SRWE produces both a smaller (Table 2) and a more variable effect than PHA, but its activity in producing transformation of "normal" lymphocytes under the conditions employed appears unequivocal.

Table 2 shows that MGE also is active in producing $\left[{ }^{3} \mathrm{H}\right] \mathrm{TdR}$ uptake by leukocyte cultures of human subjects lacking symptoms of grass pollenosis and with negative skin tests. Indeed, MGE produced significantly higher geometric

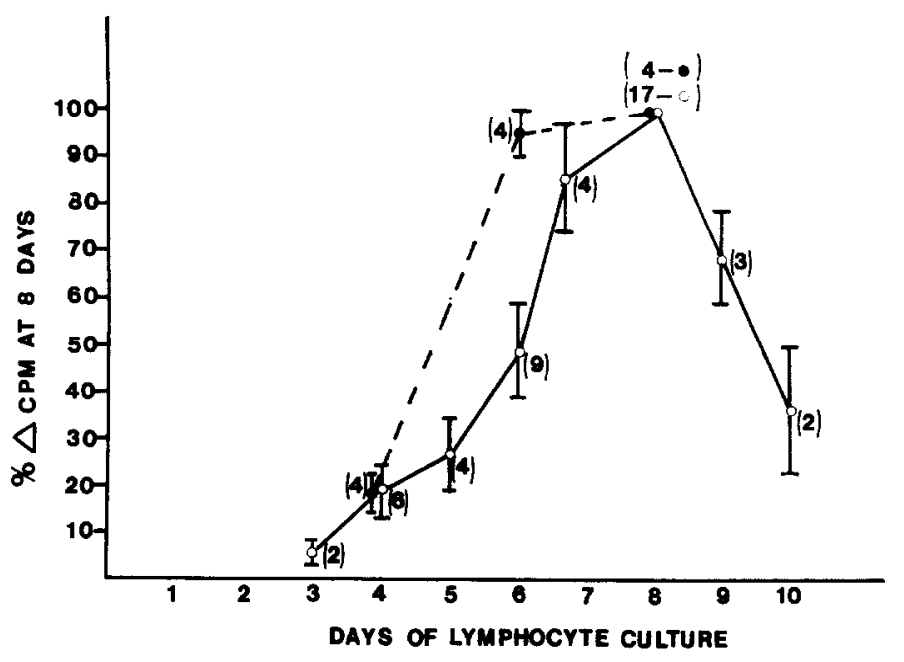

FIG. 1. $\left[{ }^{3} \mathrm{H}\right] \mathrm{TdR}$ uptake by "normal" lymphocytes after varying periods of culture. The data are normalized to show the percentage ( \pm SEM) of the change in counts per minute at 8 days in the same experiment with SRWE or MGE (O-O) or PPD (- - - The numbers in parentheses indicate the number of experiments, each comprising triplicate cultures, on which the data points are based. The geometric mean change in counts per minute at 8 days was 12,848 with pollen extract and 7244 with PPD. 


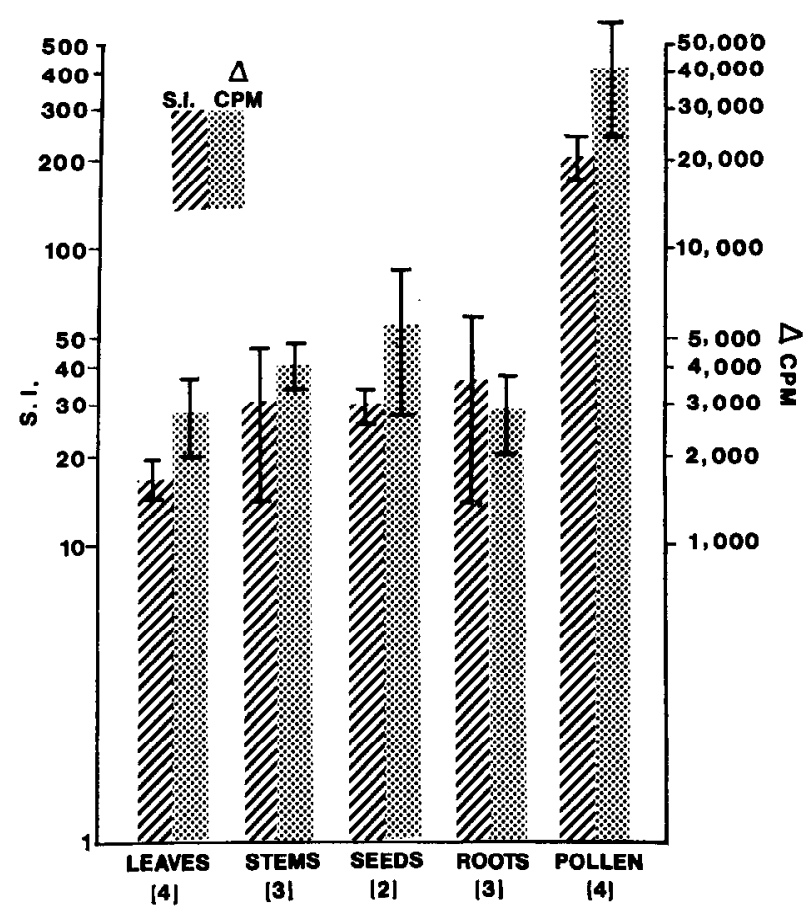

FIG. 2. Results of lymphocyte stimulation with ragweed plant extracts ( \pm SEM) of NPBL cultures with optimal concentrations of stems, seeds, roots, and pollen of short ragweed ( $\mathrm{Am}$ brosia elatior). The numbers in brackets indicate the number of experiments, each comprised of triplicate cultures.

mean SIs and changes in counts per minute than did SRWE $(P<0.05$ and $<0.01$, respectively, by Student's $t$ test). The lowest SI with an optimal amount of MGE was 32.8 and the lowest change in counts per minute was 7014 in 14 experiments.

Considering the large number of publications in which tuberculin-negative individuals failed to give lymphocyte transformation with PPD, our results in this group were especially surprising (Table 2). In these 67 experiments, the SI was under 10 in eight cases, and under 3 in only three instances; the change in counts per minute was less than 1000 in 14 of the 67 experiments. Although these results demonstrated unequivocal lymphocyte stimulation under the conditions employed, the mean SIs and changes in counts per minute shown in Table 2 indicate significantly less marked stimulation than with SRWE $(P<0.05$ and $P<0.01$, respectively). This was confirmed by finding higher SIs and changes in counts per minute with SRWE than with PPD in 24 of 27 experiments where both materials were used.

\section{Conditions Required}

Time. Figure 1 shows $\left[{ }^{3} \mathrm{H}\right] \mathrm{TdR}$ uptake by "normal" lymphoctyes cultured with SRWE, MGE, or PPD for various time periods. The data have been normalized to reflect the percentage of change in counts per minute response compared to the 8-day results observed in that particular experiment. The SRWE and MGE results were similar (data combined in Fig. 1) and showed a maxi- 
mal response at 8 days, while $\left[{ }^{3} \mathrm{H}\right] \mathrm{TdR}$ uptake with PPD peaks at 6 to 8 days. As would be expected, PHA stimulation was greater at 3 days than at later time periods.

Stimulating agents. In three experiments the lymphocyte-transforming capacity of pollen extracts prepared in our laboratory was compared with that of extracts obtained from three commercial sources. The latter materials all were dialyzed to remove preservatives. Ragweed and grass pollen extracts from all sources proved to be active in stimulating $\left[{ }^{3} \mathrm{H}\right] \mathrm{TdR}$ uptake by lymphocyte cultures of normal individuals. In six additional experiments the activities of our pollen extracts were compared with and without 24-hr dialysis against saline. Both SRWE and MGE showed only slight or equivocal loss of capacity to induce $\left[{ }^{3} \mathrm{H}\right] \mathrm{TdR}$ uptake after dialysis. In another experiment SRWE was dialyzed for $4 \mathrm{hr}$ against water and the dialysate lyophilized; after reconstitution it had only minimal capacity to induce $\left[{ }^{3} \mathrm{H}\right] \mathrm{TdR}$ uptake. The possible effect of sterilizing by membrane filtration also was evaluated by comparing the activity of extracts routinely passed through $0.45-\mu \mathrm{m}$ Millipore filters with extract sterilized by centrifugation at $48,200 \mathrm{~g}$ for $30 \mathrm{~min}$ at $4^{\circ} \mathrm{C}$; no differences were noted.

Extending the observations with ragweed pollen, extracts were prepared in a similar manner from chopped up leaves, stems, seeds, and roots of short ragweed (Ambrosia elatior) plants collected during late August and briefly washed to remove most adherent pollen grains. These plant extracts did produce a significant transformation of NPBL $(P<.001$ compared to controls), though optimal concentrations were less active than pollen extract in the same experiments (Fig. 2).

Most of the experiments employing PPD (Table 2) used Parke-Davis material, but essentially identical results were obtained in experiments where it was compared with TCA-precipitated, excipient, and preservative-free PPD obtained from Connaught Laboratories. In view of the unexpected ubiquity of NPBL-transforming capacity among the aforementioned agents, observations were extended to include more homogeneous substances. Throughout a wide range of concentrations, porcine insulin, bovine serum albumin, bovine $\gamma$-globulin, and crystalline egg albumin failed to stimulate NPBL $\left[{ }^{3} \mathrm{H}\right] \mathrm{TdR}$ uptake under the conditions being employed.

Cell source: observations on foreign students. Prior to the ragweed season, blood for lymphocyte cultures was obtained from seven nonatopic foreign students who had newly arrived from areas of the Orient, Near East, and South America free of clinically significant amounts of ragweed pollen. With an optimal concentration of SRWE (5-15 $\mu$ g of protein N), the mean SI was 140 (range, 9-388) and the

TABLE 3

$\left[{ }^{3} \mathrm{H}\right] \mathrm{TdR}$ Uptake by Human Umbilical Cord Blood Leukocytes

\begin{tabular}{|c|c|c|c|c|c|}
\hline \multirow[t]{3}{*}{ Stimulant } & \multirow{3}{*}{$\begin{array}{c}\text { Number } \\
\text { of } \\
\text { experiments }\end{array}$} & \multicolumn{2}{|c|}{ Stimulation Index } & \multirow{2}{*}{\multicolumn{2}{|c|}{$\begin{array}{l}\text { Change in counts } \\
\text { per minute }\end{array}$}} \\
\hline & & Mean & (Range) & & \\
\hline & & & & Mean & (Range) \\
\hline SRWE & 7 & 10.0 & $(3.8-18.6)$ & 6,077 & $(996-11,780)$ \\
\hline Palm pollen & 5 & 10.3 & $(5.8-23.4)$ & 6,165 & $(1,176 \cdot 12,692)$ \\
\hline PPD (6 days) & 7 & 3.1 & $(0.9-6.0)$ & 862 & $(0-2,779)$ \\
\hline PHA (6 days) & 7 & 109 & $(12.3-448)$ & 38,552 & $(575-64,876)$ \\
\hline
\end{tabular}




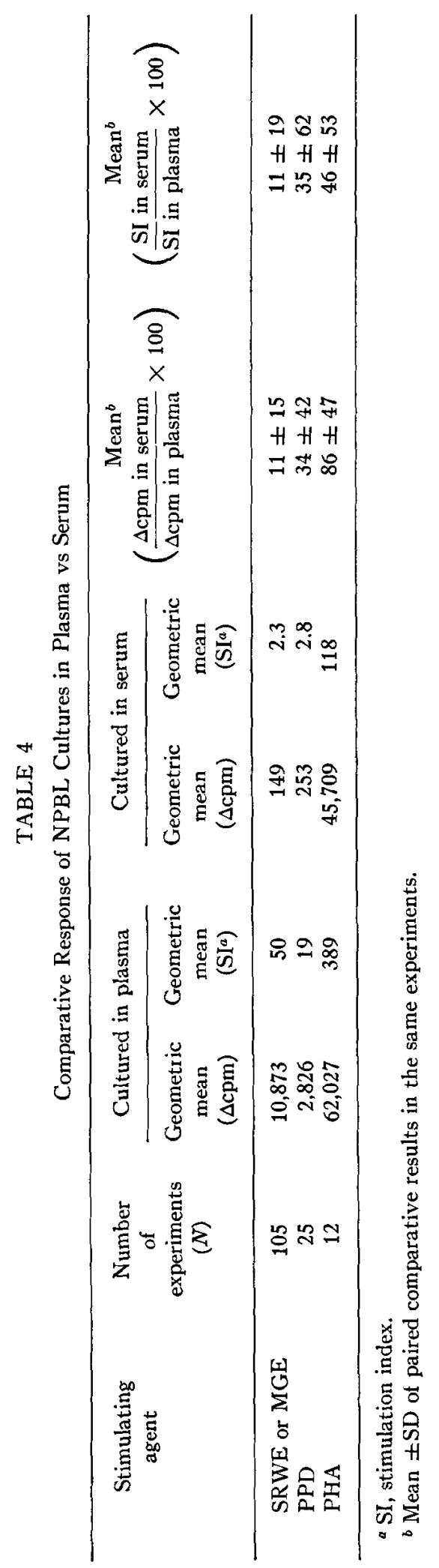


mean change in counts per minute was 24,883 (range, 422-107,509). By analysis of variance these values exceeded the controls by a significant degree $(P<0.005)$. These results are comparable with those obtained with native subjects (Table 2 ). Cultures of umbilical cord blood leukocytes. As shown in Table 3, SRWE produced a significant uptake of $\left[{ }^{3} \mathrm{H}\right] \mathrm{TdR}$ by leukocytes obtained from heparinized human cord blood $(P<0.001$ by analysis of variance), though there was less pronounced lymphocyte stimulation than with cells of adult donors (cf. Table 2 ). Similar results were obtained with an extract of palm pollen (Phoenix dactylifera), which is not indigenous to this area.

Method of lymphocyte culture. Omission of dextran routinely used to sediment the RBC did not influence the results obtained with SRWE or PPD. Likewise cells from defibrinated blood or specimens anticoagulated with EDTA also yielded similar results provided the cells were washed free of EDTA before culture. Brief osmotic lysis of the RBC remaining in the leukocyte suspension also did not influence the results.

The procedure used for washing the NPBL before culture did significantly influence the results. In 17 experiments employing SRWE or PPD, three washings with Eagle's MEM (buffered with Hanks' solution without plasma or serum) resulted in a mean decrease of $78 \%$ in change in counts per minute as compared with unwashed or once washed NPBL. The variability of triplicate cultures also increased with repeated washings. Somewhat in contrast, the change in counts per minute of PHA-stimulated cells decreased only about one-third as much after three washings. Further experiments employing three washes of MEM containing $5 \%$ autologous plasma or FCS showed less loss of reactivity, but $\left[{ }^{3} \mathrm{H}\right] \mathrm{TdR}$ uptake still was much less than when the cells were washed only once.

In nine experiments utilizing NPBL cultured with SRWE, tightly stoppered tubes incubated in room air were compared with loosely capped tubes in a $5 \%$ $\mathrm{CO}_{2}$ incubator; the change in counts per minute averaged $66 \%$ less in the $\mathrm{CO}_{2}$ atmosphere. In four similar comparisons, PPD cultures showed a $37 \%$ mean decrease in change in counts per minute. In contrast, in seven of the same experiments suboptimal amounts of $\mathrm{PHA}$ produced a $433 \%$ greater mean increase in change in counts per minute when NPBL were cultured 8 days in $5 \% \mathrm{CO}_{2}$ instead of in tightly stoppered tubes. At the end of 8 days, the MEM medium in tightly stoppered tubes cultured with SRWE had a $\mathrm{pH}$ averaging 7.78 , while after a similar period in the $5 \% \mathrm{CO}_{2}$ incubator the $\mathrm{pH}$ averaged 7.02. In view of this, it is not surprising that a relatively greater $\left[{ }^{3} \mathrm{H}\right] \mathrm{TdR}$ uptake was noted with SRWE or PPD cultures in the $\mathrm{CO}_{2}$ chamber when MEM with HEPES buffer was used.

The following conditions relating to harvesting the lymphocyte cultures in general did not appear to be critical in obtaining the type of results reported above with NPBL and SRWE or PPD : labeling time with [ $\left.{ }^{3} \mathrm{H}\right] \mathrm{TdR}$ from 2 to $24 \mathrm{hr}$, various solubilizers and scintillation fluids, $\left[{ }^{3} \mathrm{H}\right] \mathrm{TdR}$ of varying specific activity, differing counts of added $\left[{ }^{3} \mathrm{H}\right] \mathrm{TdR}$, adding excess cold thymidine at the time of harvesting the cultures, adding carrier normal human serum before precipitating with TCA, precipitating with $5 \% \mathrm{TCA}$, and washing the TCA precipitate with methanol before solubilizing it.

Culture medium. In seven experiments cultures of once washed NPBL gave significantly less incorporation of $\left[{ }^{3} \mathrm{H}\right] \mathrm{TdR}$ with ragweed extract $(P<0.01)$ when Eagle's MEM for suspension cultures (MEM-S) was substituted for Eagle's 
MEM. This is in striking contrast to the consistently enhanced stimulation produced by PHA in four experiments employing this medium. A major difference between Eagle's MEM and Eagle's MEM-S is the higher $\mathrm{Ca}^{2+}$ content of the former. Medium 199 and RPMI-1640 generally gave a lower $\left[{ }^{3} \mathrm{H}\right] \mathrm{TdR}$ uptake with SRWE than did Eagle's MEM, but the results were variable; streptomycin used in the medium did not influence the results.

Plasma or serum used in culture. In none of the 16 experiments did SRWE or PPD produce WBC stimulation when FCS from two sources was substituted for AP in the culture medium; nor did heat-inactivated or dialyzed FCS suffice. On the other hand, in all of six experiments SRWE or PPD produced essentially the same amount of $\left[{ }^{3} \mathrm{H}\right] \mathrm{TdR}$ uptake in cultures with normal human plasma as with AP. When AP was heat inactivated at $56^{\circ} \mathrm{C}$ for $30 \mathrm{~min}$, responsiveness to SRWE or PPD was markedly reduced or eliminated in 12 experiments, while PHA responses in two experiments were approximately halved. Although $15 \%$ AP sometimes sufficed for maximal stimulation with SRWE, 20\% AP (or more) generally was required for optimal $\left[{ }^{3} \mathrm{H}\right] \mathrm{TdR}$ uptake.

Of major potential importance was the observation that substitution of human serum for plasma in the culture medium resulted in a markedly diminished response of NPBL to pollen extract or PPD. The data in Table 4, based on comparisons in the same experiments, show geometric mean changes in counts per minute for SRWE and PPD in plasma which differ significantly from the geometric mean changes in counts per minute in serum $(P<0.01$ and $P<0.01$, respectively, by Student's $t$ test of log-transformed data); likewise the geometric mean SIs for SRWE and PPD are significantly greater in plasma than in serum $(P<0.01$ and $P<0.01$, respectively). In contrast, the geometric mean changes in counts per

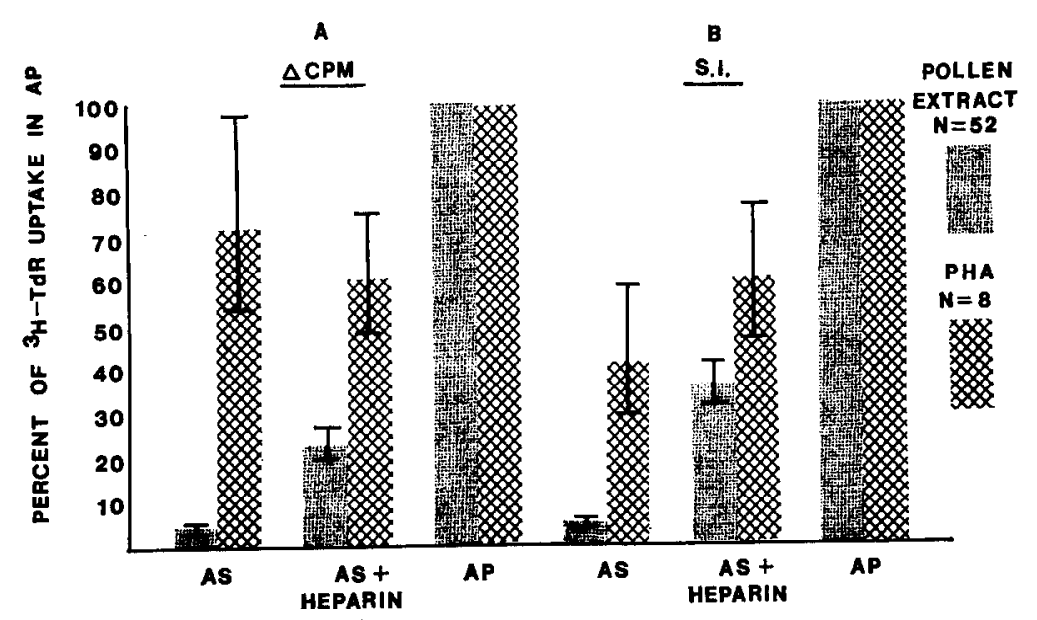

FIG. 3. Comparison of $\left[{ }^{3} \mathrm{H}\right] \mathrm{TdR}$ uptake of NPBL cultured with pollen extract (SRWE or MGE) or PHA simultaneously in autologous serum (AS), autologous plasma (AP), or autologous serum plus heparin. The absolute values of the geometric mean changes in counts per minute in AP were 9550 for pollen extract and 61,659 for PHA; the respective geometric mean SI values were 54.9 and 389 . The data in the figure have been normalized by assigning a value of $100 \%$ to results in AP in each experiment. (A) Results in terms of the geometric mean percentage changes in counts per minute \pm SEM. (B) Results in terms of the geometric mean percentage SIs \pm SEM. 
minute with PHA do not differ significantly between serum and plasma $(P>0.20)$. Consequently the ratio of change in counts per minute in serum/change in counts per minute in plasma is significantly higher in PHA-stimulated cultures than in cultures incubated with pollen extract $(P<0.01)$ or PPD $(P<0.01)$ (Table 4, column 7). However, the geometric mean SI following PHA was significantly greater in plasma than in serum $(P<0.02)$ partly due to lower control values in plasma (see below). In 12 experiments employing tuberculin- or ragweed-sensitive subjects, $\left[{ }^{3} \mathrm{H}\right] \mathrm{TdR}$ uptake with PPD or SRWE in plasma generally was substantially greater than in serum, though PPD produced about equal (and very high) uptake in both plasma and serum in one subject with very pronounced PPD skin test reactivity.

Role of heparin. To determine whether the heparin in plasma might account for the increased reactivity to pollen extracts or PPD by NPBL, $\left[{ }^{3} \mathrm{H}\right] \mathrm{TdR}$ uptake by cultures in autologous serum and autologous plasma was compared with simultaneous cultures in which heparin was added to serum. Experiments with pollen extracts (Fig. 3) again showed markedly higher changes in counts per minute and SIs when AP rather than AS was included in the culture medium, but the change in counts per minute in AS + heparin also significantly exceeded the change in counts per minute in AS alone $(P<0.01$ by Student's $t$ test of the log-transformed data). Likewise, the SIs of AS + heparin were significantly higher than those of AS alone $(P<0.01)$. Thus, heparin significantly increased the $\left[{ }^{3} \mathrm{H}\right] \mathrm{TdR}$ uptake of NPBL cultures with pollen extracts in AS, but the resulting degree of leukocyte stimulation was significantly less than in AP. It may be noted in Fig. 3 that the addition of heparin to AS had more of an effect on the SI than on the change in counts per minute. This resulted from the fact that heparin regularly decreased the control counts per minute values, thus increasing the SIs. This may be related to the long-known antimitotic properties of heparin (23), but this effect was overcome by the addition of the pollen extracts or other mitogenic substances.

It also should be noted that the values in Fig. 3 are probably underestimates of the effect of heparin in that an optimal quantity of the anticoagulant was not ascertained in each experiment. When different amounts of heparin were added to AS, the optimal quantity varied in different experiments but generally was in the range of $25-37 \mathrm{U} / \mathrm{ml}$ of AS. This was closely similar to the $26 \mathrm{U}$ of heparin $/ \mathrm{ml}$ of plasma used in the usual cultures employing AP. Similar results were obtained with three different lots of heparin from one commercial source (Riker) and also with heparin from another source (Connaught Laboratories). Sodium and ammonium heparins (Scientific Products No. B2950) gave similar results, and AP prepared with dialyzed heparin still supported marked $\left[{ }^{3} \mathrm{H}\right] \mathrm{TdR}$ uptake with SRWE and PPD. In contrast, in eight experiments PHA-stimulated cultures showed no significant increase in change in counts per minute or SIs when heparin was added to cultures in AS (Fig. 3).

To delineate further the role of heparin, experiments were carried out in which the cultured WBC were exposed either simultaneously or sequentially to heparin and SRWE. Table 5 shows one such experiment in which, after a 30-min incubation with the indicated agents, the cells were washed once and cultured for 8 days in the same or an altered combination of heparin, SRWE, and serum. Of special note is the failure of the cultures to show stimulation when heparin was not included in the culture medium at the same time as was SRWE (line 7 , Table 5). 
TABLE 5

Effect of Changing Culture Components after 30 min on $\left[{ }^{3} \mathrm{H}\right] \mathrm{TdR}$ Uptake at 8 Days

\begin{tabular}{llrrr}
\hline Initial components & $\begin{array}{c}\text { Components after } \\
\text { one wash at 30 min }\end{array}$ & $\begin{array}{c}\text { Counts per } \\
\text { minute at } \\
8 \text { days }\end{array}$ & $\begin{array}{c}\text { Change in } \\
\text { counts per } \\
\text { minute }\end{array}$ & $\begin{array}{c}\text { Stimulation } \\
\text { index }\end{array}$ \\
\hline (1) Heparin + serum & Heparin + serum & 147 & & \\
(2) SRWE, heparin + & $\begin{array}{l}\text { SRWE, heparin + } \\
\text { serum }\end{array}$ & 14,886 & 14,719 & 100 \\
(3) Serum & Serum & 944 & & \\
(4) SRWE + serum & SRWE + serum & 416 & $<0$ & $<1$ \\
(5) Heparin + serum & SRWE, heparin + & 16,486 & 16,339 & 111 \\
(6) Heparin + serum & Serum & 626 & & \\
(7) Heparin + serum & SRWE + serum & 287 & $<0$ & $<1$ \\
\hline
\end{tabular}

In additional experiments (not shown) of similar design, it was found that cells cultured for 30 min with SRWE, heparin, and serum or with SRWE and AP showed significant $\left[{ }^{3} \mathrm{H}\right] \mathrm{TdR}$ uptake at 8 days when the medium was changed at $30 \mathrm{~min}$ to contain just serum and SRWE. This indicates that, although heparin must be present simultaneously with SRWE, its effect is relatively rapid and irreversible: It need not be continuously present with SRWE throughout a prolonged period of culture. However, preincubating heparin with SRWE or PPD prior to adding them to the cultures did not enhance cell stimulation.

In view of the reported activity of sodium warfarin, as well as heparin, in influencing cutaneous delayed hypersensitivity reactions (24), this drug was added to culture medium containing autologous serum in concentrations ranging from 2 to $200 \mu \mathrm{g} / \mathrm{ml}$, but there was no enhancement of $\left[{ }^{3} \mathrm{H}\right] \mathrm{TdR}$ uptake by NPBL cultured with pollen extracts. Anticoagulants which bind calcium cannot be substituted for heparin in these cultures.

Requirement for continued presence of SRWE in cultures. In 12 experiments NPBL cultures containing SRWE were centrifuged after varying periods of time, and the cells were resuspended in fresh medium without additional SRWE. Removing SRWE in this manner after periods of $2,6,24$, or $72 \mathrm{hr}$ generally resulted in marked reduction in $\left[{ }^{3} \mathrm{H}\right] \mathrm{TdR}$ uptake, but replacement with fresh medium without SRWE at 6 days increased $\left[{ }^{3} \mathrm{H}\right] \mathrm{TdR}$ uptake.

Lymphocytes recovered from Ficoll-Hypaque gradients. In seven comparative experiments, NPBL ( $>95 \%$ lymphocytes) recovered from Ficoll-Hypaque gradients (25) showed comparable or greater changes in counts per minute in culture in AP with SRWE or PPD than in simultaneous cultures of unfractionated leukocytes containing the same number of lymphocytes; SIs of the separated cells tended to be lower due to higher control counts. Surprisingly, however, the FicollHypaque-separated lymphocytes did not show significantly diminished stimulation in AS as compared with AP: In nine experiments employing SRWE the change in counts per minute in AS was $85 \%$ of that in AP and the SI was $148 \%$ of the AP value, and in six experiments using PPD the respective values were 127 and $189 \%$. This differs sharply from the results shown in Table 4 for unfractionated leukocytes and from six concomitant experiments where simultaneous cultures of unseparated cells from the same donors with SRWE or PPD 
showed much lower changes in counts per minute and SIs in AS than in AP. Good stimulation in AS was obtained regardless of whether Ficoll-Hypaque sedimentation was employed with whole blood, leukocyte-rich plasma after gravity sedimentation, or leukocytes obtained after sedimentation with dextran. The possibility was considered that residual Ficoll or Hypaque remaining with these washed lymphocyte preparations might augment $\left[{ }^{3} \mathrm{H}\right] \mathrm{TdR}$ uptake in a manner analogous to the effect of heparin. However, this could not be confirmed in eight experiments in which varying amounts of Ficoll or Hypaque were added to cultures containing either AS or AP and incubated with SRWE or PPD.

\section{DISCUSSION}

The reported experiments demonstrate unequivocally and reproducibly that SRWE, MGE, and PPD can produce very substantial $\left[{ }^{3} \mathrm{H}\right] \mathrm{TdR}$ uptake and lymphocyte blast transformation by NPBL. These results differ from many reports in which cells from sensitized individuals, but not normal subjects, were stimulated by pollen (1-17). However, minor degrees of NPBL transformation have been noted by others $(6,17)$, and Buckley et al. (26) recently have reported preliminary data showing marked responsiveness to ragweed antigen $E$ by the lymphocytes of normal subjects after 8 or more days in culture under conditions rather different from those used in our studies. Parker et al. (27) found in testing extracts of 90 types of seeds from 38 botanical families that significant lymphocyte transformation was induced by five members of the Leguminosae as well as four species from other families: Datura discolor (Solanaceae), Trixis californica (Compositae), Ephedra nevadensis (Ephedraceae), and Mammea safra (Clusiaceae). Hashem and Kabarity (28) also found five types of legumes to produce lymphocyte transformation, while members of the soya bean and pea families had minimal effects; Wisteria floribunda seeds also are mitogenic (29). House dust extracts were reported by Romagnani et al. (30) to produce lymphocyte transformation in seven of nine nonatopic controls as well as in 9 of 10 persons sensitive to this material. Likewise May and Alberto (31) found that lymphocyte transformation produced by extracts of milk proteins and of wheat occurred commonly with the cells of both nonatopic and atopic children, its frequency and extent not differing significantly between the two groups; unwashed leukocytes were used in these experiments. Eisen et al. (32) found small but significant $\left[{ }^{3} \mathrm{H}\right] \mathrm{TdR}$ uptake by NPBL cultured with BSA, BGG, Candida, histoplasmin, TNP-BSA, DNPBSA, and fluorescein-BGG. Autoradiographs confirmed that the $\left[{ }^{3} \mathrm{H}\right] \mathrm{TdR}$ uptake was by lymphocytes, and endotoxin was excluded as the source of the responses. There also are a few reports of human NPBL stimulation by sheep red blood cells, extracts of human ocular tissue, heterologous sera, BCG, or KLH (32).

The large number of studies employing PPD usually have shown a lack of lymphocyte transformation by cells of skin test-negative donors, but a minority of reports describe human NPBL transformation in some cases (33-37). In part, this could be due simply to fewer responsive lymphocytes being required to give measurable in vitro lymphocyte transformation than to give a positive skin test in vivo (38). Nilsson (36) found almost all PPD negative persons showed substantial lymphocyte transformation in 6-day cultures with large amounts of PPD, while only cells from PPD-positive individuals transformed with smaller amounts of PPD or at shorter time intervals; this suggested the presence of cells with low affinity receptors in the PPD negative group. These observations are in accord with the reported binding of PPD by a small percentage of NPBL of humans 
(39) and unimmunized guinea pigs (40). All normal adults are reported to have circulating antibodies which bind mycobacteria antigens (41), it being suggested that these may reflect infection by saprophytic and/or avirulent mycobacteria. Immune complexes formed by these antibodies with antigens added to lymphocyte cultures could result in transformation of NPBL $(42,43)$. Lack of substantial transformation of cord blood lymphocytes by PPD (Table 3) would be in agreement with this possibility. An alternative explanation arises from Sultzer and Nilsson's evidence (44) that PPD is a B-cell mitogen in many species.

A considerable effort was made to delineate a single factor which could explain the unexpected results of our lymphocyte cultures with pollen extracts and PPD, but it would appear that a combination of several culture conditions had led to the reported findings. Factors of importance are restriction in the washing of the cells, the culture medium, and prolonged (8-day) cell culture time. In these respects, optimal conditions for pollen extracts and PPD in NPBL cultures are quite different from those which are optimal for PHA. When unfractionated leukocytes are used, the use of human plasma in the culture medium is of particular importance; human serum supports much less normal leukocyte stimulation by pollen extracts or PHD, and the results in FCS are completely negative. Heparin in plasma appears to account for part, but not all, of the plasma activity. The presence of free DNA in normal human serum, but not in plasma (45), also does not account for these differences, since adding up to $10 \mu \mathrm{g}$ of $\mathrm{DNA} / \mathrm{ml}$ of plasma at the beginning of culture did not inhibit NPBL transformation by pollen extract (experiments not shown). In contrast, NPBL separated on Ficoll-Hypaque gradients respond well to pollen extracts and PPD in serum as well as in plasma. The reason for this difference is unknown, though it might be related to the reported membrane-stablizing effect of Ficoll (46).

The prominent influence of washing the cells, the greater variability among replicate cultures, the requirement for prolonged exposure to pollen extract, and the long culture period suggest that weaker forces may bind the stimulant to the responding cell membrane in these pollen extract and PPD experiments with NPBL than is the case with PHA or other commonly employed mitogens. Nevertheless, the ultimate response in many instances is more pronounced than is usually observed in the response of sensitized lymphocytes to specific antigens. The possibility that the observed results are in fact due to acquired cellular immunity to ubiquitous antigens in nature requires consideration in spite of obtaining stimulaton with SRWE of NPBL from newly arrived foreign students from parts of the world free of ragweed pollen. This could be explained by the sharing of crossreacting antigens among pollens or other parts of plants growing throughout the world; indeed, sharing of cross-reacting allergens between ragweed and other members of the large Compositae family has been suspected for a long time. On the other hand, the response of umbilical cord leukocytes to pollen extracts is cogent evidence against the hypothesis of a universal, acquired immune response to ubiquitous antigens (47). While neonatal lymphocytes have been reported to respond to some antigens (48), it seems unlikely that this would occur with a variety of pollen antigens. The possibility that the transformation of both adult and cord blood lymphocytes represents a primary in vitro immunologic response to pollen antigens is difficult to exclude (49) and is suggested by the long period of culture required. However, it generally is very difficult to achieve primary 
immune response in vitro, and the conditions employed are much different from those required to give primary responses in other systems (50).

A major alternative possibility is that mitogens in pollen extracts produce the observed lymphocyte transformation. If so, it is puzzling that all of the five disparate types of pollen extract tested (two not shown) produced substantial responses. This implies either that there are numerous unrecognized mitogens in nature, that there are a restricted number of mitogens common to a variety of pollens, or that the observed activity is due to contaminating substance(s). The latter possibility merits serious consideration in view of the extraneous substances in these crude pollen extracts. Accordingly, viruses, trace metals, and LPS were excluded as the major source of the lymphocyte-transforming activity by appropriate experiments to be reported elsewhere; likewise, pollen arabinogalactans or active enzymes do not appear to be involved. An additional possibility, which has not been excluded, is that cells could be triggered to transform and/or divide by suitably charged macromolecular stimulants for which there are no specific receptors on the cell membrane. This possibility is supported by the enhancing effect of heparin, a polyanion which has been reported to adhere reversibly to cell membranes (51), and the rapidly growing list of known mitogens (52-54) to include substances unlikely to have specific membrane receptors (e.g., detergents) (55). Still another possibility is the generation of "secondary mitogens" in culture through interaction between consituents of pollen extracts or PPD with plasma components. Resolution of some of these questions may be achieved from ongoing work employing pollen extract fractions and cell purifications.

\section{REFERENCES}

1. Lycette, R. R., and Pearmain, G. E., Lancet 2, 386, 1963.

2. Weiner, S., and Brasch, J., Med. J. Aust. 1, 148, 1965.

3. Zeitz, S. J., Van Arsdel, P. D., and McClure, D. K., J. Allergy 38, 321, 1966.

4. Girard, J. P., Rose, N. R., Kunz, M. L., Kobayashi, S., and Arbesman, C. E., J. Allergy $39,65,1967$.

5. Mayron, L. W., and Baram, P., J. Immunol. 98, 1274, 1967.

6. Richter, M., and Naspitz, C. K., J. Allergy 41, 140, 1968.

7. Young, S. H., Pediatrics 42, 976, 1968.

8. Brostoff, J., Greaves, M. F., and Roitt, I. M., Lancet 1, 803, 1969.

9. Brostoff, J., and Roitt, I. M., Lancet 2, 1269, 1969.

10. Maini, R. N., Dumonde, D. C., Faux, J. A., Hargreave, F. E., and Pepys, J., Clin. Exp. Immunol. 9, 449, 1971.

11. Malley, A., Wilson, B. J., Barnett, M., and Perlman, F., J. Allergy Clin. Immunol. 48, 267, 1971.

12. Firket, H., Leclercq-Foucart, J., and Beubelle, F., Acta Allergol. 26, 191, 1971.

13. Romagnani, S., Biliotti, G., Passaleva, A., and Ricci, M., Int. Arch. Allergy 44, 40, 1973.

14. Rocklin, R. E., Pence, H., Kaplan, H., and Evans, R., J. Clin. Invest. 53, 735, 1974.

14.a Romagnani, S., Biliotti, G., and Ricci, M., Clin. Exp. Immunol. 19, 83, 1975.

15. Gatien, J. C., Merler, E., and Colten, H. R., Clin. Immunol. Immunopathol. 4, 32, 1975.

16. Geha, R. S., Colten, H. R., Schneeberger, E., and Merler, E., J. Clin. Invest. 56, 386, 1975.

17. Black, P. L., Marsh, D. G., Jarrett, E., Delespesse, G. J., and Bias, W. B., Immunogenetics $3,349,1976$.

18. Weisberg, S. C., Pan, P. M., and Mathews, K. P., J. Allergy Clin. Immunol. 49, 125, 1972 (abstract)

19. Mathews, K. P., Pan, P. M., and Wells, J. H., Int. Arch. Allergy 42, 653, 1972.

20. Bach, F., and Hirschhorn, K., Science 143, 813, 1964. 
21. Phillips, G. L. in "A Manual of Clinical Allergy," 2nd ed. (Sheldon, J. M., Lovell, R. G., and Mathews, K. P., Eds), p. 507. W. B. Saunders, Philadelphia, 1967.

22. Cooke, R. A., "Allergy in Theory and Practice" p. 530. W. B. Saunders, Philadelphia, 1947.

23. Regelson, W., Advan. Cancer Res. 11, 223, 1968.

24. Cohen, S., Benacerraf, B., McCluskey, R. T., and Orary, Z., J. Immunol. 98, 351, 1967.

25. Böyum, A., Scand. J. Clin. Lab. Invest. Suppl. 21, No. 97, 1, 1968.

26. Buckley, R. H., Sanal, S. D., Ownby, D. R., Becker, W. G., and Seymour, F., J. Allergy Clin. Immunol. 57, 202, 1976 (abstract).

27. Parker, J. W., Steiner, J., Coffin, A., Lukes, R. J., Burr, K., and Brilliantine, L., Experientia 25, 187, 1969.

28. Hashem, N., and Kabarity, A., Lancet 1, 1428, 1966.

29. Barker, B. E., and Farnes, P., Nature (London) 215, 659, 1967.

30. Romagnani, S., Biliotti, G., Passaleva, A., and Ricci, M., Clin. Allergy 3, 51, 1973.

31. May, C. E., and Alberto, R. A., Clin. Allergy 2, 335, 1972.

32. Eisen, S. A., Lyle, L. R., and Parker, C. W., J. Immunol. 111, 962, 1973.

33. Aspergren, N., and Rorsman, H., J. Allergy 35, 433, 1964.

34. Janicki, B. W., Aron, S. A., Schechter, G. P., and McFarland, W., Proc. Soc. Exp. Biol. Med. 141, 809, 1972.

35. Smith, J. A., and Reichman, L. B., Amer. Rev. Resp. Dis. 106, 194, 1972.

36. Nilsson, B. S., Cell. Immunol. 3, 493, 1972.

37. Sarkany, I., and IIales, H., Brit. J. Dermatol. 80, 29, 1968.

38. Oppenheim, J. J., Fed. Proc. 27, 21, 1968.

39. Witten, T. A., Wang, W. L, and Killian, M, Science 142, 596, 1963

40. Donald, D., King, D. J., and Beck, J. S., Immunology 27, 87, 1974.

41. Bardana, E. J., Jr., McClatchy, J. K., Farr, R. S., and Minden, P., Clin. Exp. Immunol. $13,65,1973$.

42. Moller, G., Clin. Exp. Immunol. 4, 65, 1969.

43. Oppenheim, J. J., Cell. Immunol. 3, 341, 1972.

44. Sultzer, B. M., and Nilsson, B. S., Nature New Biol. 240, 198, 1972.

45. Steinman, C. R., J. Clin. Invest. 56, 512, 1975.

46. Stuart, J., and Simpson, J. S., J. Clin. Pathol. 23, 517, 1970.

47. Oppenheim, J. J., Ann. Allergy 27, 305, 1969.

48. Leiken, S., Whang-Peng, J., and Oppenheim, J. J., in "Proceedings of the Fifth Leukocyte Culture Conference," (J. E. Harrig, Ed.), p. 389. Academic Press, New York, 1970.

49. Eisen, S. A., Lyle, L. R., and Parker, C. W., J. Immunol. 111, 962, 1973.

50. Mishell, R. I., and Dutton, R. W., J. Exp. Med. 126, 423, 1967.

51. Gasic, G., and Baydak, T., in "Biological Interactions in Normal and Neoplastic Growth," (Brennan, M. J., and Simpson, W. L., Eds.), p. 709. Little Brown, Boston, 1962.

52. Oppenheim, J. J., and Rosenstreich, D. L., Progr. Allergy 20, 65, 1976.

53. Wedner, H. J., and Parker, C. W., Progr. Allergy 20, 195, 1976.

54. Elves, M. E., "The Lymphocytes," 2nd ed., p. 420. Lloyd-Like, London, 1972.

55. Greene, W. C., Parker, C. M., and Parker, C. W., Cell. Immunol. 25, 74, 1976. 